\title{
Picasso's 1917 paint materials and their influence on the condition of four paintings
}

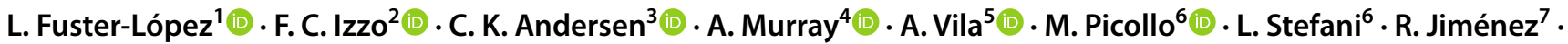 \\ E. Aguado-Guardiola ${ }^{8}$
}

Received: 4 June 2020 / Accepted: 29 October 2020 / Published online: 5 December 2020

(c) Springer Nature Switzerland AG 2020

\begin{abstract}
This work aims to investigate the correlation between the painting materials used by Picasso to create four artworks in Barcelona in 1917 and their actual conditions. Specifically, a range of crack types and patterns was observed in the painted layers. The paintings, kept together in Picasso's family house until they were donated to the Museu Picasso in 1970, had significant differences in their condition, even though they present several similarities in the choice of materials, technique and in their conservation history. A multi-analytical approach was adopted to characterise the painted layers by X-ray fluorescence spectroscopy, fibre optic reflectance spectroscopy in the 350-2200 nm range, gas chromatographymass spectrometry, and Fourier transform infrared spectroscopy. The obtained results have been combined with those from a previous analytical campaign focused on the study of grounds and canvases of these four paintings and with visual examination of the cracks to establish hypotheses about the differences in degradation. This combined overview of non-invasive documentation techniques, chemical analysis and observations of the mechanical damage has provided an insight into the possible contribution each layer could have played in the damage observed in the four canvas paintings.
\end{abstract}

Keywords Picasso $\cdot$ Canvas paintings $\cdot \mathrm{XRF} \cdot \mathrm{OM} \cdot \mu$-FTIR $\cdot \mathrm{GC}-\mathrm{MS} \cdot \mathrm{FORS} \cdot$ Failure mechanisms $\cdot$ Cracks $\cdot$ Mechanical properties

\section{Introduction}

This research presents results obtained by a multi-analytical study on the composition of paint layers in four paintings created by Pablo Picasso in Barcelona in 1917, now belonging to the Museu Picasso, compared to a descriptive analysis on the cracks observed.

The paintings, namely Seated Man (MPB110005; $104 \times 54 \mathrm{~cm})$, Man with Fruit Bowl (MPB110006;
$100 \times 70 \mathrm{~cm}$ ), Woman on an Armchair (MPB110007; $92 \times 64 \mathrm{~cm}$ ), and Blanquita Suárez (MPB1 10013; 73×47cm), have a range of crack types and patterns in the painted layers. This paper brings together the results of a previous analytical campaign performed on the grounds and canvases used by Picasso and the latest study on the paint films of the selected paintings in an attempt to shed some light on the relationship between the choice of the materials, environment conditions, failure mechanisms, and

Electronic supplementary material The online version of this article (https://doi.org/10.1007/s42452-020-03803-x) contains supplementary material, which is available to authorized users.

L. Fuster-López, laufuslo@crbc.upv.es | ${ }^{1}$ Universitat Politècnica de València, Instituto Universitario de Restauración del Patrimonio, Valencia, Spain. ${ }^{2}$ Department of Environmental Sciences, Informatics and Statistics, Ca' Foscari University of Venice, Venice, Italy. ${ }^{3}$ The Royal Danish Academy of Fine Arts, Schools of Architecture, Design and Conservation, School of Conservation, Copenhagen, Denmark. ${ }^{4}$ Art Conservation Program, Department of Art History and Art Conservation, Queen's University, Kingston, ON K7L 3N6, Canada. ${ }^{5}$ Fundació La Caixa, Barcelona, Spain. ${ }^{6}$ National Research Council, Istituto Fisica Applicata "Nello Carrara", Florence, Italy. ${ }^{7}$ Museu Picasso, Barcelona, Spain. ${ }^{8}$ Escuela de Conservación Y Restauración de Bienes Culturales de Aragón, Huesca, Spain. 


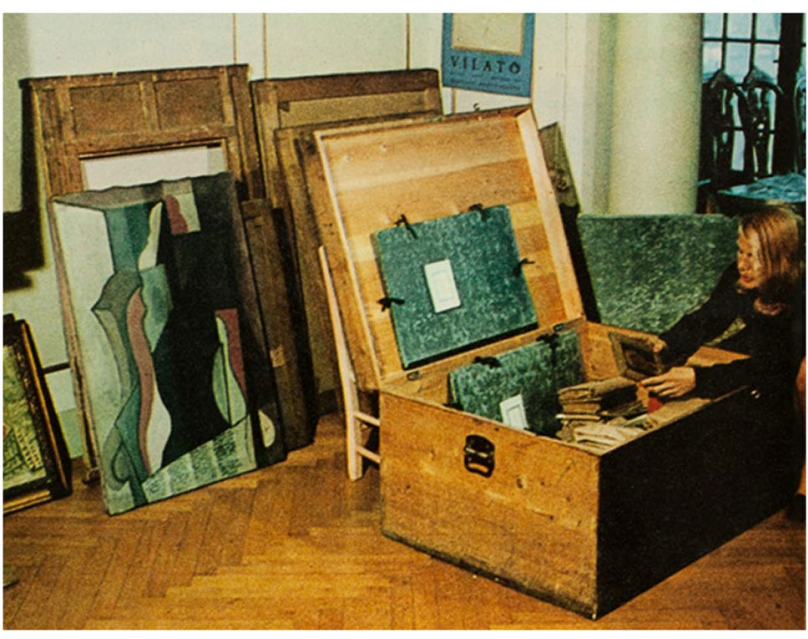

Fig. 1 Woman on an Armchair at Picasso's family house. Casa Vilató (Passeig de Gracia, 48, s/d, Barcelona). Fotografia de J. Francès Estorch. Fons Joan Vidal Ventosa, Museu Picasso, Barcelona. () of the reproductions of works by Pablo Picasso: Pablo Picasso's Estate. VEGAP. Madrid, 2020. Permission to reproduce courtesy of VEGAP

degradation patterns. The main aim was to determine whether differences in the composition of the paints could have contributed to the variation in degradation shown by each painting.

The selected paintings were created during Picasso's stay in Barcelona (June-November 1917) in a cubist style. In this period, Picasso often worked in Rafael Martinez Padilla's studio. This aspect is of utmost relevance. The existing documentation indicates that Picasso did not have his own studio; therefore, he did not re-use any canvas (as he commonly did) and had to purchase all the painting materials including canvases, brushes, turpentine and oil paints. This could explain the narrow palette used, limited to seven colours (white, black, brown, red, yellow, green and blue) plus two more colours resulting from their combination (grey and beige). Given the geometric and colour similarities, these four paintings represent a series within the group of 11 paintings created in Barcelona in 1917 , leading to this comparative study. When Picasso returned to Paris, the paintings were stored in his family house until they were donated to the Museu Picasso in Barcelona in 1970, the institution that still owns the works [1-3] (Fig. 1). One final aspect relevant to the selection of these case studies is that the paintings are mounted on the original stretchers and no evidence of conservation treatments prior to this donation has been found. In 2016 the museum noticed the need to consolidate only one of the paintings, namely Seated Man, due to extensive cracking and fear of paint loss.

Considering that paintings are complex, heterogeneous, multi-layered, and dynamic systems, identifying the composition and material properties of the different layers of a painting is critical in the understanding of degradation processes and products as well as their interactions $[6,8]$. A previous study by the authors focused on the relationship between the composition and the physical-mechanical properties of painting support materials (canvases and the ground layers) used by Picasso in the four paintings [4]. The results had showed that, in all cases, the artist painted on cotton canvases and applied two ground layers. The organic composition of the grounds mainly consisted of animal glue, mixed with small amounts of drying oils and polysaccharide compounds. In the four paintings, the bottom ground layer was richer in binding media than the upper one. In particular, the upper ground layer of Man with a Fruit Bowl was mainly composed of a zinc ( $Z n)$ containing compound, whereas the upper ground layer in the three other paintings was mainly composed of lead white and other materials including calcite. This had probably caused the slight differences in the tone of the four ground layers, ranging from grey to orange tinges. The previous work already addressed some hypotheses about the difference in crack patterns observed in the paintings (Table 1) linked to the presence of either $\mathrm{Zn}$ or lead $(\mathrm{Pb})$ in the grounds [7], the amount of animal glue in ground layers, and the degree of tightness in the canvas weave [4-6].

In this study, a multi-analytical study was carried out to study the colour palette of the four paintings, prioritizing the use of non-invasive techniques such as in-situ X-ray fluorescence spectroscopy (XRF) and fibre optic reflectance spectroscopy (FORS). Moreover, a small number of micro-samples from each painting was analysed by optical microscopy (OM) and gas chromatography-mass spectrometry (GC-MS). Micro-Fourier transform infrared spectroscopy ( $\mu$-FTIR) analysis was also performed, when there was a sufficient amount of remaining sample. In this way, the results obtained through elemental analyses were combined with the spectroscopic and chromatographic

Table 1 Overall description of the crack patterns observed in the four paintings

\begin{tabular}{llll}
\hline Seated Man (MPB1 10005) & Woman on an Armchair (MPB110007) & $\begin{array}{l}\text { Man with a Fruit } \\
\text { Bowl (MPB110006) }\end{array}$ & Blanquita Suárez (MPB110013) \\
\hline $\begin{array}{l}\text { Extensive cracks through paint } \\
\begin{array}{l}\text { and ground layers over the entire } \\
\text { surface }\end{array}\end{array}$ & $\begin{array}{l}\text { Local cracks narrow in brown paint as } \\
\text { well as two scratches and one local area } \\
\text { of impact cracks }\end{array}$ & $\begin{array}{l}\text { No cracks } \\
\text { Predominantly local impact and } \\
\text { handling cracks through paint } \\
\text { and ground layer }\end{array}$ \\
\hline
\end{tabular}



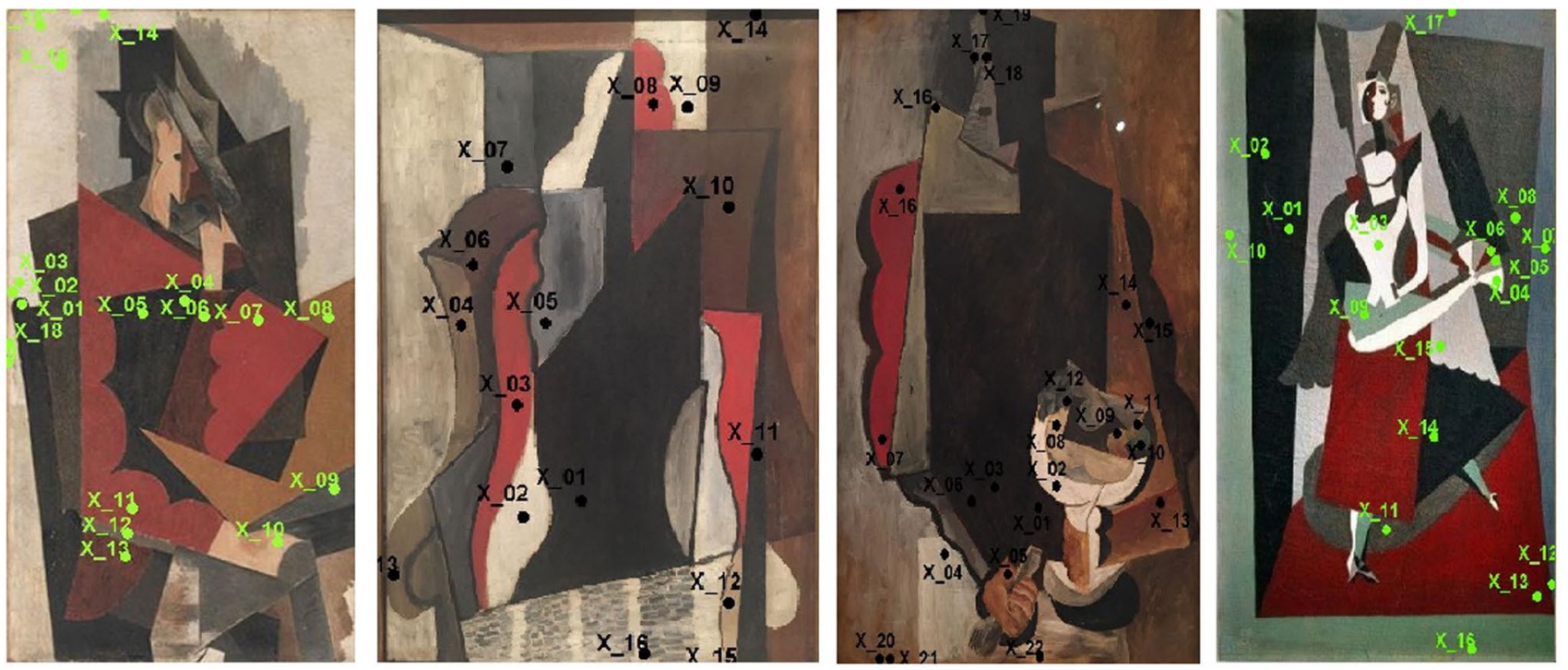

Fig. 2 XRF spot analysis. @ of the reproductions of works by Pablo Picasso: Pablo Picasso's Estate. VEGAP. Madrid, 2020. Permission to reproduce courtesy of VEGAP

results, allowing the identification of the palette and the binding media used by the artist.

\section{Methods}

In situ elemental analysis was performed non-invasively with portable Elio X-ray fluorescence equipment by XGlab $X$ and Gamma Ray Electronics, which has been successfully applied on modern and contemporary paintings [8]. The paint examination was performed directly on the surface of the areas marked in Fig. 2. The analysis was carried out in air, with a sample area of $1 \mathrm{~mm}$ diameter, $100 \mathrm{~s}$ acquisition live-time at $40 \mathrm{kV}$ and $100 \mu \mathrm{A}$, using an Rh-target without filtration.

Non-invasive fibre optics reflectance spectroscopy was also used on three paintings (Man with Fruit Bowl, Woman on an Armchair and Blanquita Suárez) to confirm and complement XRF elemental information. Two Zeiss spectroanalysers, models MCS601 UV-NIR and MCS611 NIR 2.2 WR, mounted on a single chassis, were used for this study. Measurements were acquired in the 350-2200 nm range. The light source was a tungsten lamp (model CLH600) with a colour temperature of about $3000 \mathrm{~K}$ and an emission interval of between 320 and $2500 \mathrm{~nm}$. An opticalfibre-fused anhydrous quartz band was used to send and receive electromagnetic radiation from the analysed area. The $8^{\circ} / 8^{\circ}$ probe-head was used only for the system calibration (99\% diffuse reflectance Spectralon ${ }^{\circledR}$ standard). Measurements on paintings were collected without the probehead to avoid any contact with the surface of the painting.
A small number of micro-samples from the painted layers of the four artworks were collected to identify the inorganic and organic binding media. The samples were analyzed by micro-Fourier transform infrared spectroscopy $(\mu-\mathrm{FTIR})$ in attenuated total reflectance (ATR) and transmittance mode with a Thermo Fisher Scientific Nicolet iN10 MX Ultra Fast Motorized stage with MCT Detector. The spectra were acquired between 4000 and $600 \mathrm{~cm}^{-1}, 128$ scans, with a resolution of $4 \mathrm{~cm}^{-1}$.

The organic binding media was also analysed by GC-MS using an Agilent 6890NGC instrument with a capillary HP-5 (5\%-phenyl)-methylpolysiloxane column ( $30 \mathrm{~m}, 0.25 \mathrm{~mm}$, $0.25 \mu \mathrm{m})$, interfaced with an Agilent 5973NetworkMS. The temperature programme was set from $80^{\circ} \mathrm{C}$ to $315^{\circ} \mathrm{C}$, $10^{\circ} \mathrm{C} / \mathrm{min}$. The MS was run in FullScan mode $(\mathrm{m} / \mathrm{z} 50-600)$, $1.9 \mathrm{scans} / \mathrm{s}$. The transfer line was at $280^{\circ} \mathrm{C}$ and the source temperature was $150^{\circ} \mathrm{C}$. Electron ionisation energy was $70 \mathrm{eV}$. Quantitative GC-MS analysis was performed using nonadecanoic acid as the internal standard. The paint samples were transestherified using (trifluoromethylphenyl)trimethylammonium hydroxide ( $2.5 \%$ in methanol), overnight reaction as described in [9-11]. The following molar ratios between the most significant fatty acids were calculated: palmitic to stearic acid (P/S), azelaic to palmitic $\operatorname{acid}(\mathrm{A} / \mathrm{P})$, oleic to stearic acid $(\mathrm{O} / \mathrm{S})$ and azelaic to suberic acid (A/Sub) ratios, as reported also in [a-d]. The obtained data were compared to previous results obtained by the authors on twentieth century artists oil paints as described in [11-13].

For image processing, the areas homogeneous in colour were defined and for each of them the contour lines were first processed, trying to enhance the differences between 
light and dark areas. Then, the images were desaturated (in grayscale), modifying the references 'black' (0) and 'white' (255) to highlight the cracks.

\section{Results}

Table 1 gives an overall description of the crack patterns observed in the four paintings. As mentioned, different degradation phenomena were observed in the paintings.

Even though all the paintings had been stored in the unstable environment of the same house, only the painting Seated Man showed such extensive damage. The fact that the cracks were over the entire surface but less pronounced in areas protected by the stretcher bar along the edge, suggests that the damage was environmentally induced. If this is the case, the interesting question is why the other three paintings do not show the same degree of damage. One explanation may be that the composition of materials is different and therefore caused this painting to be more affected by the ambient environment.

In this section, the results for the pigments and binders of different paints from the four paintings are presented. Considering the previous study of the canvas supports and ground layers [4], this multi-analytical study is intended to identify the composition and condition of the paint film, as well as to investigate if the paint layer could have had any impact in the cracks observed in the four paintings.

\subsection{Picasso's Palette}

XRF and FORS are non-invasive, effective, and rapid methods to determine the tentative pigment composition [18-20]. This section describes all possible pigments detected in the painted areas and Table 2 gives the results for each specific painting.

$\mathrm{XRF}$ analysis on the four paintings showed that $\mathrm{Pb}$ was the main element in the white painted layers, suggesting the presence of the basic lead (II) carbonate, lead white $\left(2 \mathrm{PbCO}_{3} \cdot \mathrm{Pb}(\mathrm{OH})_{2}\right)$. This was also confirmed by FORS and FTIR results (due to the characteristic IR bands at 1450 $\mathrm{nm}$ as well as at around 3530,1390 and $680 \mathrm{~cm}^{-1}$ ). In some white areas, barium ( $\mathrm{Ba}$ ) was also detected, more probably as barite (barium sulphate, $\mathrm{BaSO}_{4}$ ) used as a filler mixed with lead white. In other white areas, XRF results revealed $\mathrm{Zn}$ and $\mathrm{Ba}$, which could be associated with the presence of lithopone or the presence of barite and a zinc-based compound. FORS and XRF found lead white also in the grey and beige hues. Moreover, in two of the three beige painted areas, an iron (III) hydroxideoxide-based pigment was identified [21, 22]. Similarly, in the grey areas of two paintings, FORS found iron oxides. XRF identified relatively low amounts of silicon
(Si) and possibly titanium (Ti) in some grey areas, where FORS identified the presence of alumino-silicates, due to the presence of very weak absorption bands in the $1380-1420 \mathrm{~nm}$ range that could be related to the first overtones of the hydroxyl stretching vibration mode. The presence of titanium could be related to impurities of earth pigments [23].

In one case, Woman on an Armchair, the bluishgrey paint was tentatively identified by FORS as a mixture of a carbon-based pigment and ultramarine blue $\left(3 \mathrm{Na}_{2} \mathrm{O} .3 \mathrm{Al}_{2} \mathrm{O}_{3} \cdot 6 \mathrm{SiO}_{2} \cdot 2 \mathrm{Na}_{2} \mathrm{~S}\right)$. This blue pigment was detected by FTIR as well, due to the peculiar absorptions at around $970,690,650$, and $580 \mathrm{~cm}^{-1}$. Its presence could explain the grey tone of the paint.

Regarding the black pigments used in three of the four paintings, the presence of calcium (Ca) and phosphorous $(P)$ is likely associated with the use of an ivory or bone black pigment $\left(\mathrm{Ca}_{3}\left(\mathrm{PO}_{4}\right)_{2}+\mathrm{CaCO}_{3}+\right.$ carbon (C)) as the main black pigment. Moreover, iron-based pigments were also detected in some of the black areas. It was not possible to perform FTIR analysis to corroborate this finding.

In the red and brown areas analysed, iron (Fe) and mercury $(\mathrm{Hg})$ were the main elements detected by XRF. This indicated a mixture of an iron (III) oxide-based pigment, such as Mars red, and vermillion (both confirmed by FORS).

Yellow and green pigments were present only in Man with a Fruit Bowl and Blanquita Suarez and mainly contain chromium ( $\mathrm{Cr}$ ). The presence of $\mathrm{Cr}$ in green areas was related to the viridian pigment $\left(\mathrm{Cr}_{2} \mathrm{O}_{3} \cdot 2 \mathrm{H}_{2} \mathrm{O}\right)$ as found by FORS. Viridian, more transparent and vivid than the chrome oxide green pigment, was also used in the time period and was stable (18). Strontium (Sr) and Fe were also detected in Man with a Fruit Bowl in some of the yellow and green areas analysed, indicating the presence of strontium yellow $\left(\mathrm{SrCrO}_{4}\right)$ and iron-based compounds. Commercially, strontium yellow (strontium chromate) was often mixed with other pigments, such as Prussian blue $\left(\mathrm{Fe}_{4}\left[\mathrm{Fe}(\mathrm{CN})_{6}\right]_{3}\right)[24]$.

Blue areas were observed only in Blanquita Suárez. These resulted to contain a mixture of compounds containing Zn, Zn oxide and/or Zn sulphide, and a blue pigment. The blue pigment was identified as ultramarine blue by FORS and also in previous research by scanning electron microscopy with energy dispersive X-ray spectroscopy (SEM-EDX) on a cross-section from the same area of the painting [25]. This finding was also corroborated by FTIR analysis. Ultramarine blue was also tentatively identified by FORS in some of the grey areas of Woman on an Armchair. 


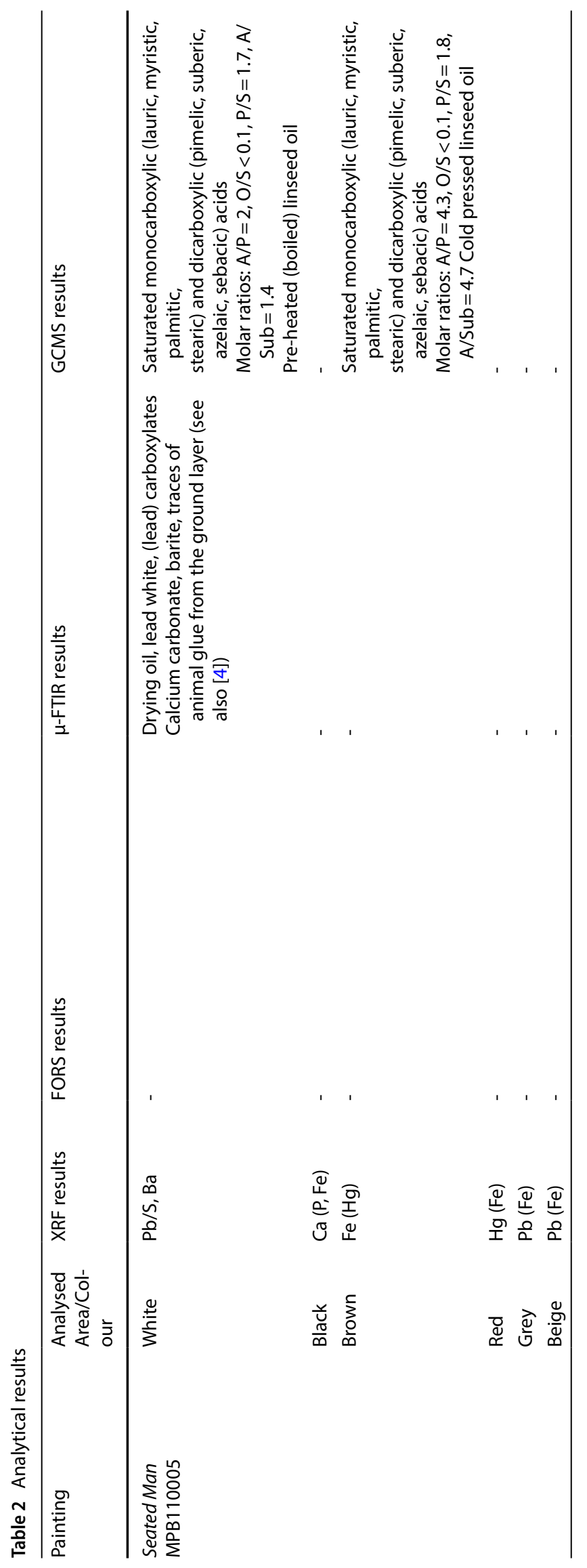




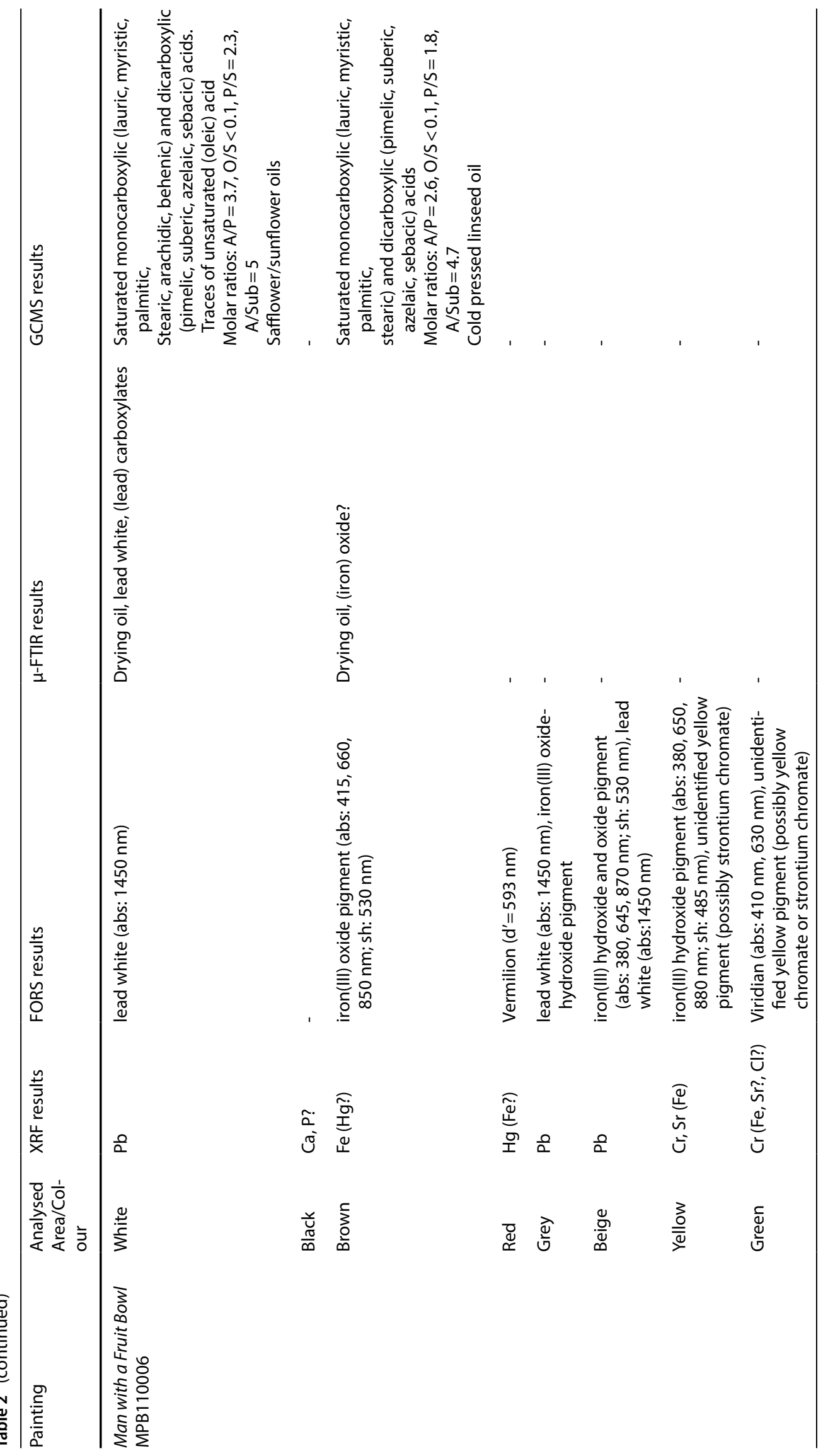

SN Applied Sciences

A SPRINGER NATURE journal 


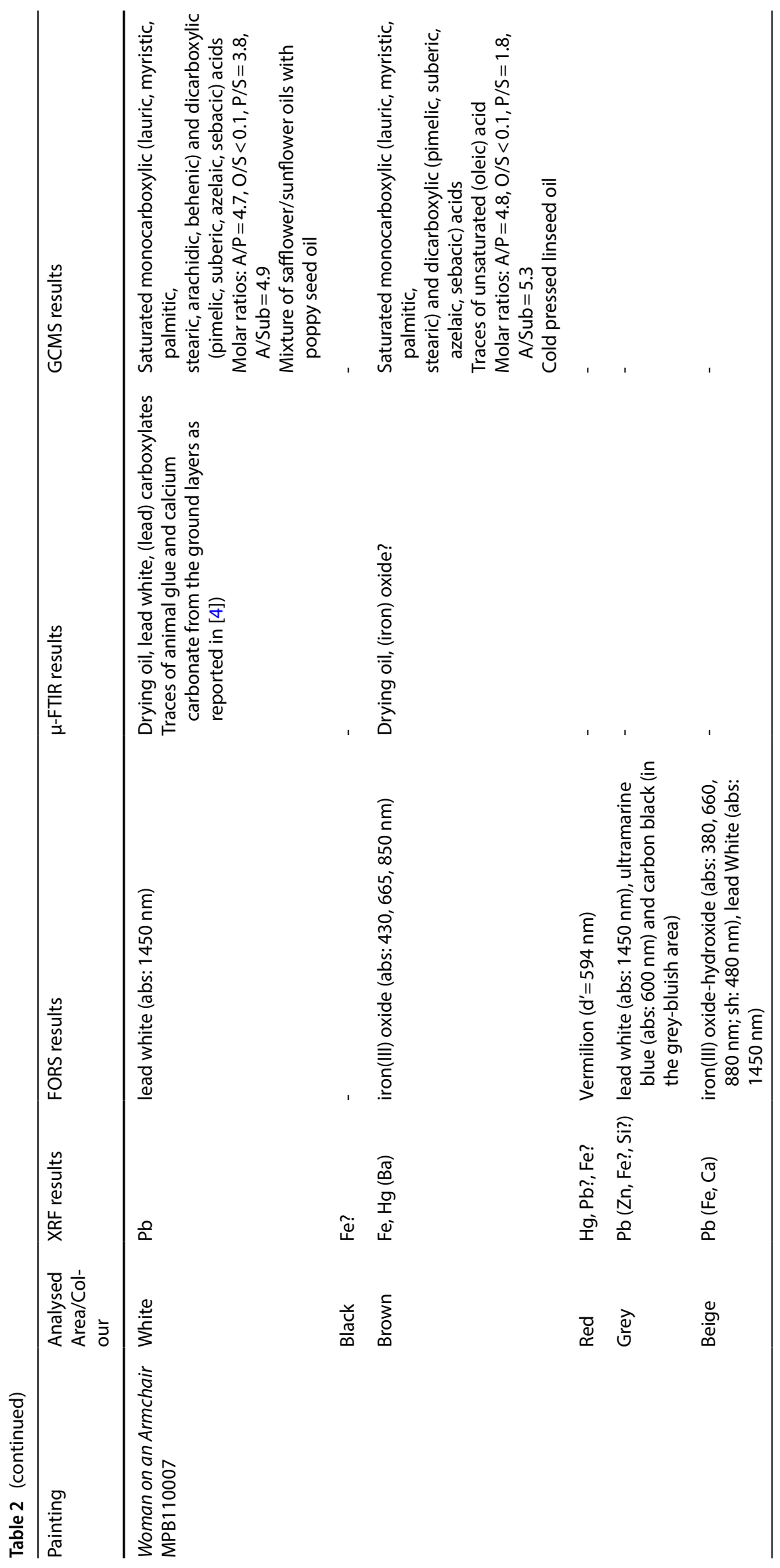




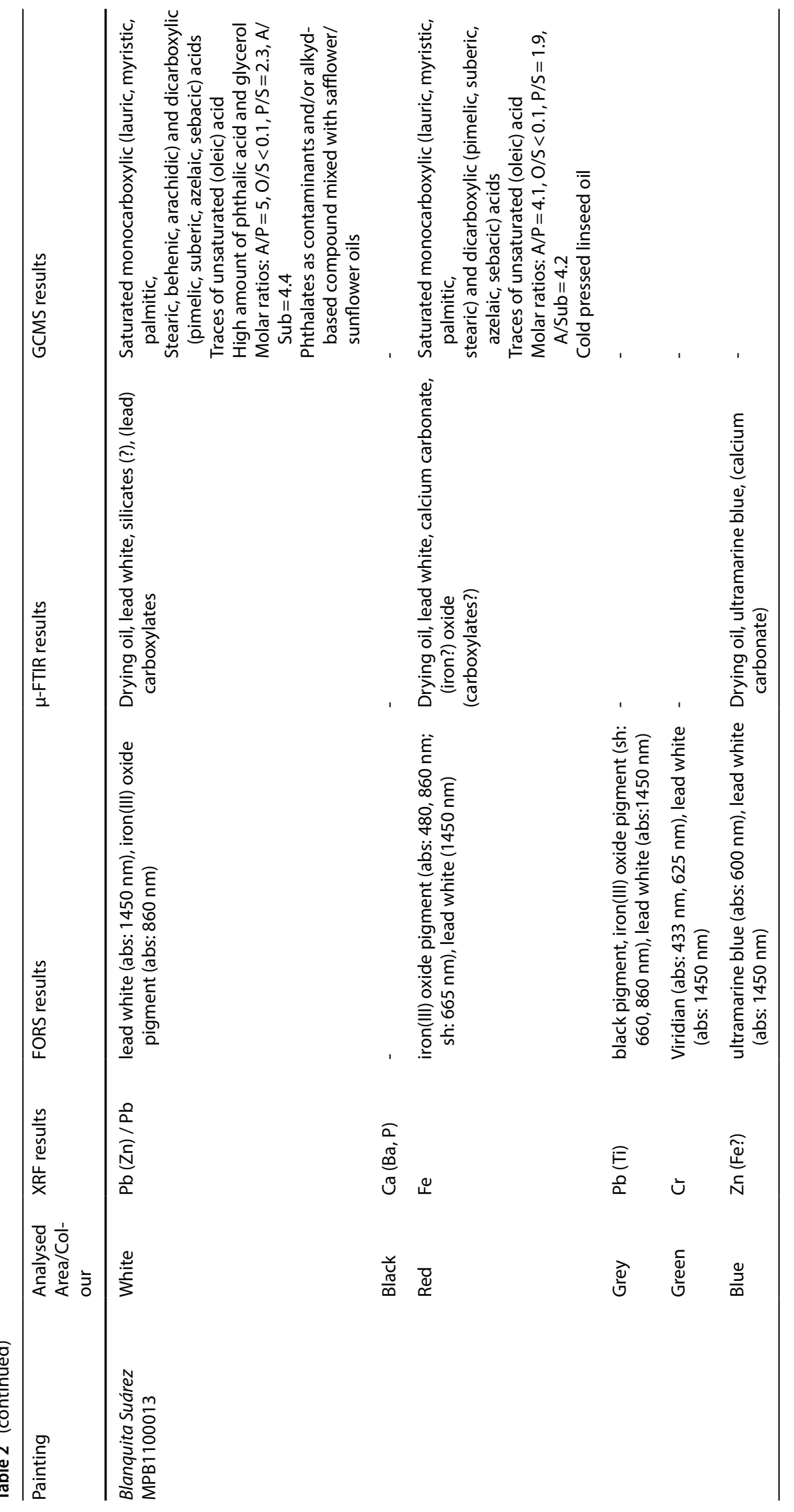

SN Applied Sciences

A SPRINGER NATURE journal 


\subsection{Binding media}

As reported in Table 2, FTIR and GCMS analysis of microsamples showed that the examined paints were bound in lipid media. The IR spectra showed the typical absorptions due to the presence of lipid-based binding media, in particular those at 2921, 2850 (stretching $\left.-\mathrm{CH}_{2} \mathrm{CH}_{3}\right), 1729$, 1708 (stretching $\mathrm{C}=\mathrm{O}$ ) and $1166 \mathrm{~cm}^{-1}$ (stretching $\mathrm{C}-\mathrm{O}$ ) [26].

GCMS results provided further details about their composition according to the fatty acids profile. Table 2 lists the GCMS results and reports the ratios between azelaicto-palmitic acid (A/P), oleic-to-stearic acid $(\mathrm{O} / \mathrm{S})$ and palmitic-to-stearic acid (P/S) and azelaic-to-suberic acid (A/ Sub) which are generally used for the characterisation of drying oils [11, 27-29].

All the analysed paint samples from Seated Man, Man with a Fruit Bowl, and Woman on an Armchair were characterised by the typical composition of a polymerised drying oil paint, with saturated mono-saturated fatty acids (mirystic acid, lauric acid, palmitic acid, stearic acid), difatty acids (azelaic acid, suberic acid, sebacic acid), and traces of unsaturated oleic acid [30-32]. The calculated $A / P$ ratios were generally higher than 3 which indicated a high degree of oxidation: azelaic acid, in fact, is the most abundant product formed upon oxidation and polymerisation of unsaturated fatty acids present in fresh drying oils. In the same way, the O/P ratios were in all cases lower than 0.1 , suggesting that the lipid networks were well polymerised and only very low amount of unsaturated oleic acid was still present. In this sense, the presence of lead-based compounds, detected both in ground layers [4] and in the pigments from the painted layers (see XRF, FORS and FTIR results in Table 2), may have catalysed the polymerisation and the oxidation processes.

Although the identification based only on the $\mathrm{P} / \mathrm{S}$ ratios is not always completely reliable for modern and contemporary oil paints [11,13-17], some indications about the type of oils can be provided. The brown paints, having $\mathrm{P} / \mathrm{S}$ ratios values ranges between 1.8 and 1.9 , were likely bound in linseed oil. For the whites, due to the calculation of $\mathrm{P} / \mathrm{S}$ ratios and the identification of specific fatty acids (arachidic and behenic acids), safflower and/or sunflower oils and poppy seed oils were likely detected in Man with a Fruit Bowl and Woman on an Armchair, respectively. These findings concur with specific literature reporting that, in general, white and blue pigments were bound in poppyseed, safflower and sunflower oils, to avoid yellowing occurring in linseed oil during curing [33-35]. According to the obtained A/Sub ratio [29], the presence of a preheated linseed oil was identified in Seated Man: only in this case, in fact, the A/Sub value was 1.4 , referring to a pre-treatment by cooking or boiling the vegetable oil.
The red paint in Blanquita Suárez was bound in linseed oil. The white paint appeared to be a mixture of dryingsemi-drying oils (safflower and sunflower oils, as seen for other white paints) containing phthalic acid and glycerol in a high amount. An explanation for the presence of this compound has not yet been determined: phthalic acid is indeed a very common environmental contaminant and not necessarily a paint constituent, but its significant presence could be related to the use of an alkyd-based compound. However, this needs further research as alkyd paints were introduced into the art market only later in the 1930s [36-40].

Another important consideration related to the organic fraction is the detection of carboxylates, also known as metal soaps. In particular, lead soaps were observed due to the typical FTIR absorption peak at around $1530 \mathrm{~cm}^{-1}$ : these carboxylates had likely formed as products after the reaction of metal ions (from lead white pigment) and the carboxylic acids after hydrolysis of the fatty acid moieties in the triglycerides of drying oils [41]. That the formation of metal carboxylates has strong implications for the conservation of twentieth century paintings is well known and, thus, further research is needed to monitor eventual conservation problems which could occur in Picasso paintings.

\section{Discussion of experimental results and surface visual observation}

According to the analytical results (Table 2), all four paintings had a similar palette with few traditional colours and where the areas painted white mainly contained lead white. Black pigments were primarily identified as organic pigments, including ivory black or bone black. Greys and beiges were mixtures of whites, blacks and some other pigments from the palette, giving warmer or colder hues to the paint. The browns and reds were mainly iron oxides and vermilion. The yellow and greens are chromiumcontaining pigments, in some cases mixed with other pigments. Finally, the blue pigments analysed were also mixtures of pigments where ultramarine was the main blue identified. The identified pigments matched those found in other Picasso paintings studied from the same time period [39, 42-44]. The four paintings were in a cubist style, with uniform areas of colour. The paint was applied thinly and, from observation of the surface, with one or very few layers. This painting style made it possible to 

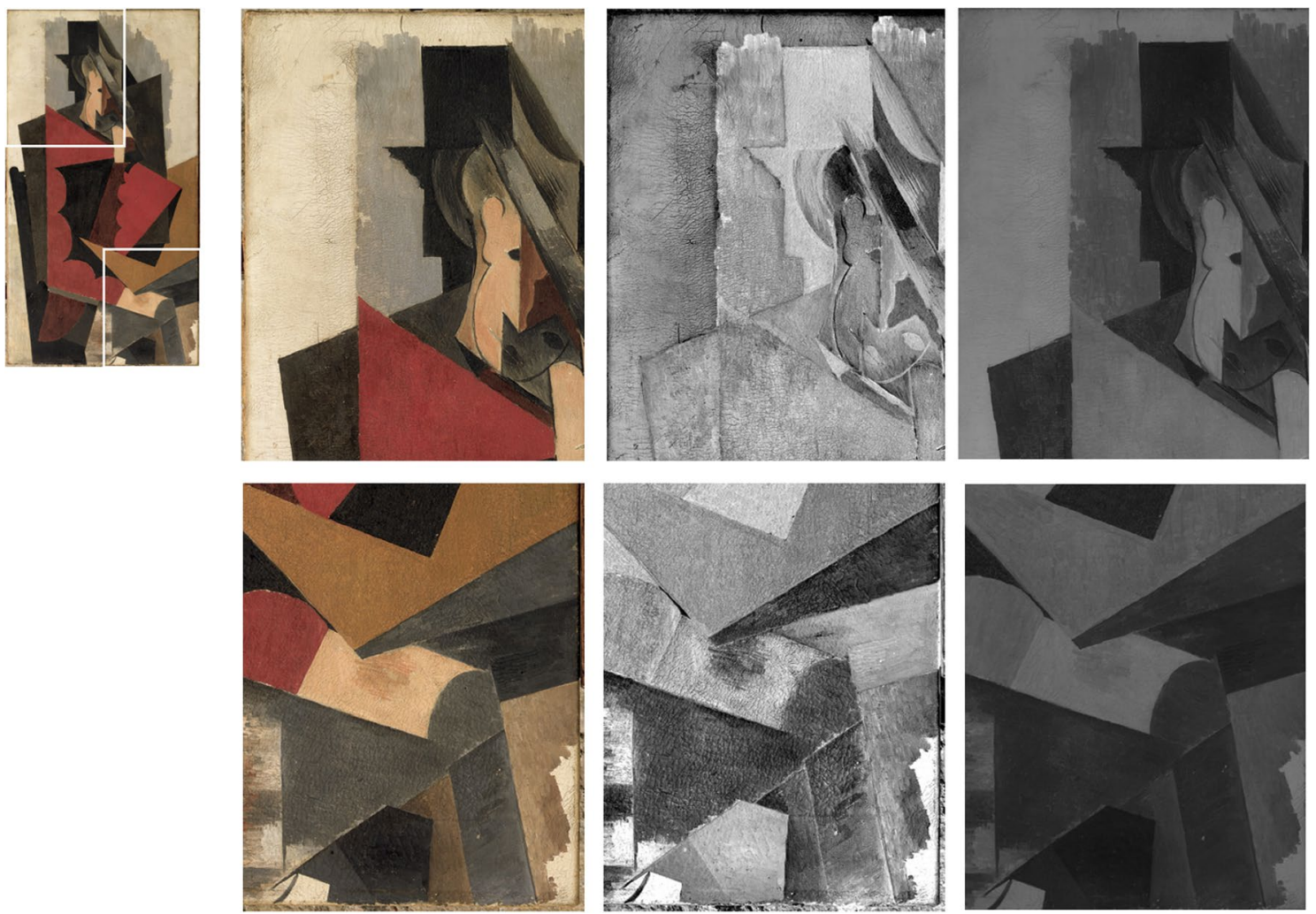

Fig. 3 Seated Man (visible, enhanced Vis and IR image of two relevant areas) ๑ of the reproductions of works by Pablo Picasso: Pablo Picasso's Estate. VEGAP. Madrid, 2020. Permission to reproduce courtesy of VEGAP

study whether certain pigments were more likely to cause cracking than others, bearing in mind that slight differences in the paint thickness can contribute to the depth of the cracks and the size of paint islands observed as was observed in recent studies $[45,46]$.

A general overview of the four paintings showed that Seated Man (Fig. 3) had suffered the most deterioration, with an extensive cracking that required consolidation in 2016. The high proportion of animal glue in or below the ground, in combination with the tightly woven canvas observed in a previous study [4] might have been the cause for the significant response of this painting to humidity fluctuations. Either the tendency of the canvas to shrink at high humidity or the significant internal stresses that hide glue builds-up at low humidity might have contributed to the extent of cracking observed.

A close observation of enhanced Vis images ${ }^{1}$ showed interesting features and allowed a precise description of damage found. There was less cracking in the areas over the stretcher bars and at the edges, most probably because of the barrier effect created by the stretcher, which would have minimised the effects of environmental

\footnotetext{
${ }^{1}$ Enhanced Vis images were obtained from Seated Man and Blanquita Suárez only since these paintings have the most prominent features that allowed the image processing.
}

fluctuations in the painting materials. In such areas, only the corner cracks were noteworthy, as well as some local concentric cracks resulting from the tacking nails in the edges; these were not due to re-stretching and had developed in the ground layer only, not in the paint later. Overall, there were more cracks on the figure's right-hand side than the left-hand side, possibly due to exposure to a deleterious environment.

Regarding the crack pattern observed, cracks in the paint were mostly shallow and therefore considered to be the result of chemical reactions within the pigmented layers; thus, some differences in the degree of cracking were noted between paint colours. The crack network over the entire painted surface was present in all colours, including red and black areas. The corresponding red and black areas in the other three paintings did not show cracks, which suggests that the paint layers alone were not responsible for creating the forces that caused failure and supports the idea of the type and extent of damage being the result of the interaction between paint, ground, and canvas. Also, different colours varied in the degree (extension, size and depth) of cracking. For example, the red and black areas had more cracks than many of the other colours of this painting. It was also observed that the amount of cracking varied within 
areas where there were subtle variations in colours. In general, there appeared to be fewer cracks in many of the grey areas compared with the black ones. There were no cracks in the lower grey face and fewer cracks in the dark grey section of the slanted hat rim, near the face. This was also noticeable in the lighter (and less red) flesh-coloured face and the area just down and to the figure's left, which had fewer cracks. An early hypothesis has been to consider possible pigment interactions in the paint film. XRF analysis showed the presence of greater amounts of lead white in both areas. Previous studies have suggested that ion migration could take place between adjacent paint layers $[7,46]$. However, further analysis, possibly in combination with spatially resolved elemental mapping, is needed to determine if lead ions from the ground could be contributing ions to the paint film. By illustrating the correlation between lead concentration and the extent of cracking, it could be possible to suggest that a significant presence of lead is responsible for a more durable paint film which
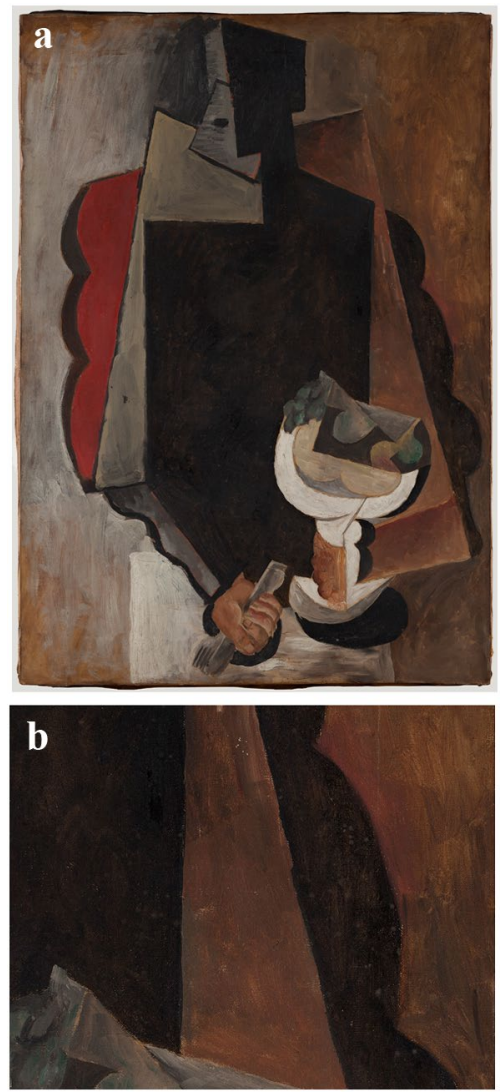

Fig. 5 a Man with a Fruit Bowl. (๑) of the reproductions of works by Pablo Picasso: Pablo Picasso's Estate. VEGAP. Madrid, 2020. Permission to reproduce courtesy of VEGAP. $\mathbf{b}$ Bright spots on top of the ochre ground and a slight speckling effect in the black areas in Man with a Fruit Bowl. $\odot$ of the reproductions of works by Pablo Picasso: Pablo Picasso's Estate. VEGAP. Madrid, 2020. Permission to reproduce courtesy of VEGAP is strong and tough, therefore less vulnerable to climate fluctuations and potential cracking. For the grey triangle in the mid-section on the figure's left side, there were no cracks, but next to this area, there were many cracks in the red and the dark black regions. Again, the presence of lead white (determined by XRF) may have contributed to strengthening the paint layer against cracks.

Previous research showed that the combination of animal glue and possibly the carboxylates found in Woman on an Armchair (Fig. 4a) could explain the large, shallow cracks observed in the paint layers as a result of a stiffer and somewhat brittle ground. Fine cracks were especially evident in two brown areas. Some cracks had also been observed in the brown, Fe-based areas in Seated Man but
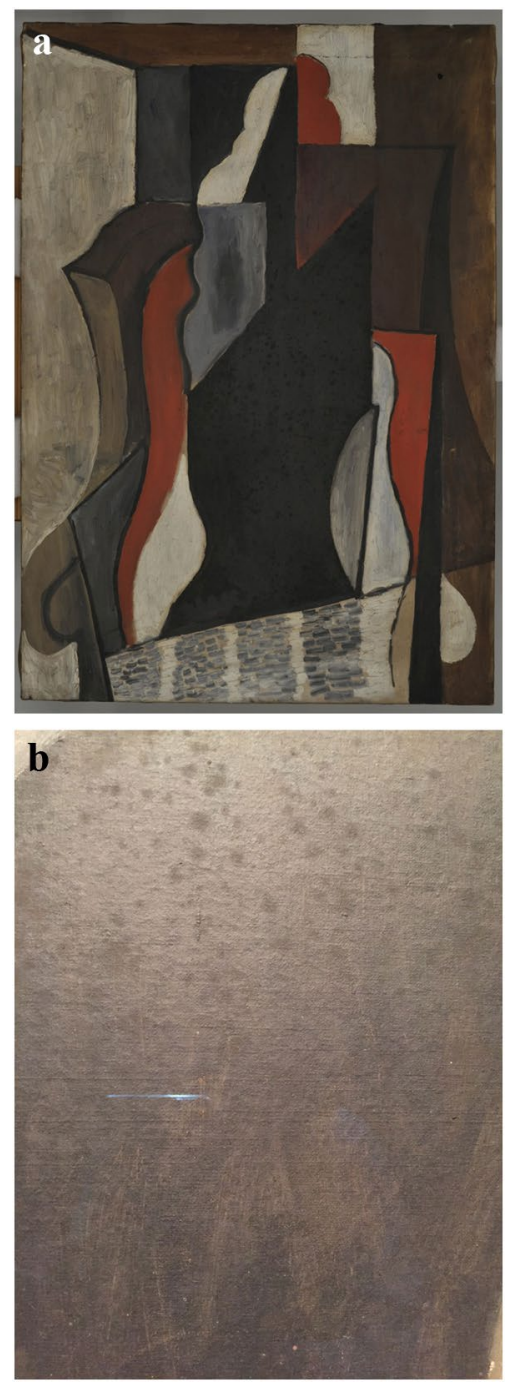

Fig. 4 a Woman on an Armchair. (c) of the reproductions of works by Pablo Picasso: Pablo Picasso's Estate. VEGAP. Madrid, 2020. Permission to reproduce courtesy of VEGAP. $\mathbf{b}$ Speckling effect in the central black areas in Woman on an Armchair. (C) of the reproductions of works by Pablo Picasso: Pablo Picasso's Estate. VEGAP. Madrid, 2020. Permission to reproduce courtesy of VEGAP 
Fig. 6 Blanquita Suárez (visible, enhanced Vis and IR image of three relevant areas). († of the reproductions of works by Pablo Picasso: Pablo Picasso's Estate. VEGAP. Madrid, 2020. Permission to reproduce courtesy of VEGAP
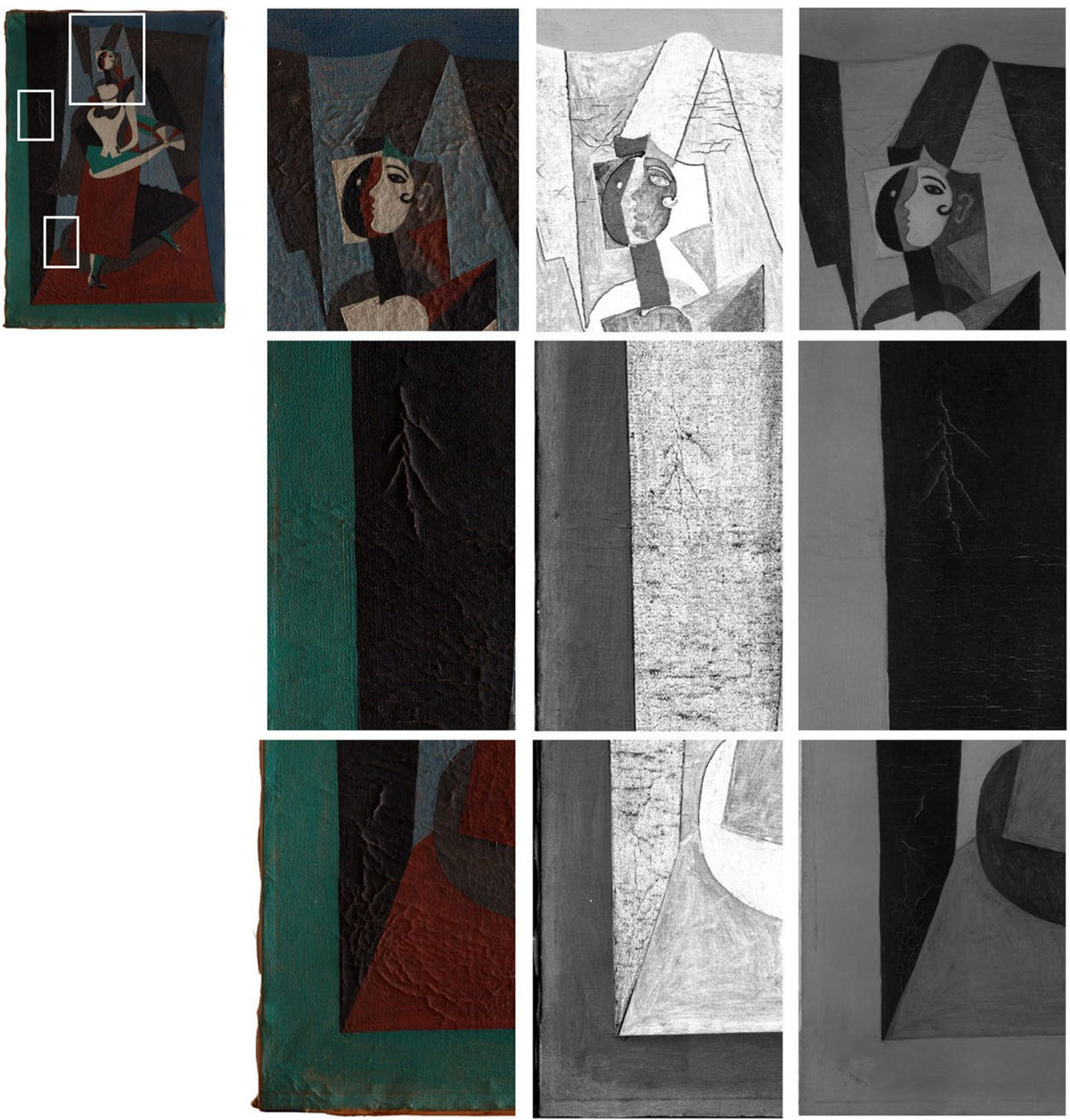

they appeared a little wider. In addition, Woman on an Armchair presented thin black and red layers together with black and white brushstrokes applied over the white preparation in the lower area of the canvas. A network of large but seemingly shallow cracks was observed in areas not coinciding with the stretcher and there were some local detachments in areas that coincided with the edges of the stretcher bars. Two larger cracks resulted from scratches from the back and one local crack pattern in the white upper left area related to impact from the back. Finally, the same speckling effect found in the central black areas was observed in Man with a Fruit Bowl (Fig. 4b).

In Man with a Fruit Bowl (Fig. 5a) there were no visible cracks. The painting presented a fine and compact paint layer with local prominent brushstrokes and no significant cracks. The zinc compound detected in the upper ground layer might explain the good condition observed in the paint layer. Research has shown that a paint layer containing zinc tends to delaminate rather than to crack; however, no evidence was found of delamination. Bright spots on top of the ochre ground, as well as a slight speckling effect in the black areas, were observed (Fig. 5b).

Blanquita Suárez (Fig. 6) showed a different crack pattern. The damage was not consistent in the same colours. Apart from presenting a richer palette of blue and green shades, deep, local cracks appeared to be predominantly in certain areas (the top and the bottom) that may not be attributed to the environment and paint properties but most likely to mechanical impact during the handling of the painting, together with some pentimenti, rather than from the material components and their properties.

\section{Conclusions and future perspectives}

The present study discusses these interactions by means of an in-depth characterisation of the paint materials, the observed cracks, and the reasons for their presence in the paintings.

The cracking of Seated Man was extensive and since the composition of the paint layers in this painting was not 
significantly different from that of the three other paintings in the study, this research has not been able to show a general correlation between the damage and materials used in the paint layer. This again points to the previously demonstrated difference in ground and canvas as possible explanation for the pronounced difference in the crack pattern of this painting. Environmentally induced forces in canvas and ground glue layers are known to be dominant at high and low relative humidity compared with those from the paint layers. Since the most significantly damaged painting, Seated Man, had an overall paint layer composition similar to that of the other paintings, the differences in ground and canvas remain the most likely cause of the deep cracks (also in the ground) reported in previous work. This research, however, determined that the pigmented film had some influence on the development of local cracks observed in the paintings and thus may be attributed to different chemical and physical properties of the paint. The fewer cracks found in flesh tones and grey areas were most likely due to active metal ions from lead white forming a more durable paint film. The thickness of the paint films may affect the crack patterns, but it was not possible to verify this experimentally as it would require extensive sampling.

Man with a Fruit Bowl did not show cracks possibly because of the presence of $\mathrm{Zn}$ compounds in the top ground layer, as well as the use of a loose-weave canvas and a homogeneous, compact paint layer.

Woman on an Armchair also showed some cracks, which could be connected to the presence of carboxylates which could make the layers stiffer.

With regards to Blanquita Suarez, higher amounts of protein present in the ground can make a painting vulnerable to humidity; in combination with certain pigments, this could make paintings prone to environmentally induced damage. The dominant cracks in Woman on an Armchair and in Blanquita Suarez, however, seem to be handling-related impacts.

Pigment-binder interactions may have made the paint films more or less prone to degradation. Aspects that are being investigated related to this are possible migration of materials between paint layers, in particular metal ions from pigments and driers but also binding media from a medium-rich paint layer, that can potentially seep into the ground layer, causing free fatty acids to migrate from the lipid binding media.

Acknowledgements This study has been developed thanks to equipment granted by R+D Project HAR2016-75131-P (2017-2019) Ministerio de Economía, Industria y Competitividad de España (MICINN/ FEDER)-Programa Estatal de Fomento de la Investigación Científica y Técnica de Excelencia, Subprograma Estatal de Generación del Conocimiento. In situ non-invasive studies were performed in the framework of the AICO/2019/231 (2019-2020) Project-Programa para la
Promoción de la Investigación Científica, el Desarrollo Tecnológico y la Innovación en la Comunitat Valenciana, Conselleria de Educación, Investigación, Cultura y Deporte. Authors acknowledge preliminary studies carried out by Andrés Sánchez Ledesma (ARTE-LAB) and the higher solution images of Humberto Durán. Authors also thank Marion F. Mecklenburg (Smithsonian Institution) for interesting suggestions and technical advice and Filippo Cherubini of IFAC-CNR for his support in image processing. Sponsorship from the Museu Picasso, Barcelona, to cover permission fees for the reproduction of works by Picasso is gratefully acknowledged.

\section{Compliance with ethical standards}

Conflict of interest The authors declare that they have no conflict of interest.

\section{References}

1. Jiménez de Garnica R (2017) Las pinturas de 1917 del Museo Picasso de Barcelona: una colección singular que conserva sus rasgos de identidad". In: 18 Jornada Conservación de Arte Contemporáneo. Madrid, February 2017, Museo Nacional Centro de Arte Reina Sofía, pp. 273-282.

2. Gual M, Jiménez de Garnica R, Bru R (2017) 1917: Picasso en Barcelona. Fundació Museu Picasso, Barcelona

3. Fuster-López L, Jiménez de Garnica R, Vila A, Izzo FC, AguadoGuardiola E, Valcárcel-Andrés JC, Vicente-Escuder A, Andersen CK, Murray A, Picollo M, (2019) Con permiso de Picasso. Aproximación a los mecanismos de degradación en pintura moderna. In: 19a Jornada Conservación de Arte Contemporáneo. Madrid, Febrero 2018, Museo Nacional Centro de Arte, Reina Sofia, pp. 71-82.

4. Vila A, Murray A, Andersen CK, Izzo FC, Fuster-López L, AguadoGuardiola E, Jiménez de Garnica R, Scharff A (2019) Picasso 1917: An Insight into the Effects of Ground and Canvas in the Failure Mechanisms in Four Artworks. In: Van den Berg KJ, Bonaduce I, Burnstock A, Ornsby B, Scharff M, Carlyle L, Heydenreich G, Keune K (eds) Conservation of Modern Oil Paintings. Springer, Cham, pp 245-253

5. Mecklenburg MF (1982) Some aspects of the mechanical behaviour of fabric-supported paintings. Smithsonian year annual report of the Smithsonian Institution, Unpublished Smithsonian Institution, Washington DC

6. Bilson T (1996) Canvas shrinkage: a preliminary investigation into the response of a woven structure. In: J. Bridgeland (ed.) ICOM Committee for Conservation, 11th Triennial Meeting; Edinburgh, September 1996, James \& James Ltd, pp. 245-252.

7. Mecklenburg MF, Tumosa CS, Vicenzi EP (2013) The influence of pigments and ion migration on the durability of drying oil and alkyd paints. In: New Insights into the Cleaning of Paintings: Proceedings from the Cleaning 2010 International Conference, Universidad Politecnica de Valencia and Museum Conservation Institute. Smithsonian Institution, pp. 59-67.

8. Izzo FC, Mazzei C, Zendri E, Capogrosso V, Gironda M, Alberti R, Nodari L, Gambirasi A, Nevin A (2015) Multi-analytical non-invasive study of modern yellow paints from postwar italian paintings from the international gallery of modern art Cà Pesaro, Venice. X-Ray Spectrom 44:296-304

9. Berg J, van den Berg KJ, Boon J (1999) Chemical changes in curing and ageing oil paints. In: J. Bridgeland (ed.) ICOM Committee for Conservation, 12th Triennial Meeting; Lyon, France, 1999, James \& James Ltd, pp. 248-253. 
10. Berg J, van den Berg KJ, Boon J (2001) Determination of the degree of hydrolysis of oil paint samples using a two-step derivatisation method and on-column GC/MS. Prog Org Coat 41:143-155. https://doi.org/10.1016/S0300-9440(01)00140-0

11. Izzo FC, van den Berg KJ, van Keulen H, Ferriani B, Zendri E (2014a) Modern oil paints-formulations, organic additives and degradation: some case studies. In: Van den Berg KJ, Burnstock A, De Keijzer M, Krueger J, Learner T, De Tagle A, Heydenreich G (eds) Issues in Contemporary Oil Paint. Springer, Cham, pp 75-104

12. Izzo FC, 20th Century Artists' Oil Paints: A Chemical-Physical Survey, Dottorato di ricerca in Scienze Chimiche, XXIII ciclo, Scuola di dottorato in Scienze e Tecnologie (SDST), 2009-2010, pp. 19-24; 52-73

13. Fuster-López L, Izzo FC, Piovesan M, Yusá-Marco DJ, Sperni L, Zendri E (2016) Study of the chemical composition and the mechanical behaviour of $20^{\text {th }}$ century commercial artists' oil paints containing manganese-based pigments. Microchem J 124:962-973

14. Caravá S, Roldán García C, Vázquez de Agredos-Pascual ML, Murcia Mascarós S, Izzo FC (2020) Investigation of modern oil paints through a physico-chemical integrated approach Emblematic cases from Valencia, Spain. Spectrochimica Acta Part A: Mol Biomol Spectrosc 240(15):118633

15. Fuster-López L, Izzo FC, Damato V, Yusá-Marco DJ, Zendri E (2019) An insight into the mechanical properties of some modern cobalt blue paint films. J Cult Herit 35:225-234

16. Izzo FC, van den Berg KJ, van Keulen $\mathrm{H}$, Ferriani $B$, Zendri $E$ (2014b) $20^{\text {th }}$ century artists' oil paints: the case of the Olii by Lucio Fontana. J Cult Herit 15:557-563

17. Izzo FC, Balliana E, Pinton F, Zendri E (2014) A preliminary study of the composition of commercial oil, acrylic and vinyl paints and their behaviour after accelerated ageing conditions. Conserv Sci Cult Herit 14:353-369

18. Bacci M, Boselli L, Picollo M, Radicati B (2009) UV, VIS, NIR Fibre Optic Reflectance Spectroscopy (FORS). In: Pinna D, Galeotti M, Mazzeo R (eds) Practical handbook on diagnosis of paintings on movable support. European Project ARTECH. Centro Di, Firenze, pp 197-200

19. Liritzis I, Zacharias N (2011) Portable XRF of archaeological artifacts: current research, potentials and limitations. In: X-Ray Fluorescence Spectrometry (XRF) in Geoarchaeology. Springer, New York, NY, pp 109-142

20. Appoloni CR, Blonski MS, Parreira PS, Souza LAC (2007) Pigments elementary chemical composition study of a Gainsborough attributed painting employing a portable X-rays fluorescence system. AIP Conf Proc 884:459-464

21. Carlesi S, Bartolozzi G, Cucci C, Marchiafava V, Picollo M (2013) The artists' materials of Fernando Melani: a precursor of the Poor Art artistic movement in Italy. Spectrochim Acta A: Mol Biomol Spectrosc 104:527-537

22. Helwig K (1988) Iron Oxide Pigments (natural and synthetic). In: Berrie BH (ed) Artists' pigments, A Handbook of Their History and Characteristics, vol 4. Archetype publications, London, pp 39-109

23. Eastaugh $\mathrm{N}$ et al (2004) Pigment Compendium. A Dictionary of Historical Pigments, Elsevier Butterworth-Heinemann, Oxford

24. Conservation \& Art Materials Encyclopedia Online (http:// cameo.mfa.org/wiki/Main_Page CAMEO: Conservation_.26_ Art_Materials_Encyclopedia_Online) Accessed on: 15 January 2020

25. Sanchez A (2016) Estudio de los materiales presentes en micromuestras tomadas de las pinturas sobre lienzo tituladas Hombre sentado, Hombre con frutero. Unpublished report, Mujer en un sillón y Blanquita Suárez

26. van der Weerd J, van Loon A, Boon J (2005a) FTIR studies of the effects of pigments on the aging of oil. Stud Conserv 50(1):3-22
27. Mills J, White R (2012) Organic chemistry of museum objects. Oxford, Routledge

28. Izzo FC, Zendri E, Biscontin G, Balliana E (2011) TG-DSC analysis applied to contemporary oil paints. J Therm Anal Calorim 104(2):541-546

29. Colombini MP, Modugno F (eds) (2009) Organic mass spectrometry in art and archaeology. Wiley, London

30. Wexler H (1964) Polymerization of drying oils. Chem Rev 64(6):591-611

31. Schilling MR, Khanjian HP, Carson DM (1997) Fatty acids and glycerol content of lipids: effects of aging and solvent extraction on the composition of oil paints. Laboratoire de recherche des musées de France, Paris

32. Berg JVD (2002) Analytical chemical studies on traditional linseed oil paints. Molart series, Netherlands Organization for Scientific Research

33. Carlyle LA (2001) The artist's assistant: oil painting instruction manuals and handbooks in Britain 1800-1900, with reference to selected Eighteenth-century sources. Archetype, London

34. Mayer R (1991) The artist's handbook of materials and techniques. Viking, USA

35. Tumosa CS, Mecklenburg MF (2005) The influence of lead ions on the drying of oils. Stud Conserv 50(sup 1):39-47

36. Cappitelli F, Koussiaki F (2005) THM-GCMS and FTIR for the investigation of paints in Picasso's Still Life, weeping woman and nude woman in a red armchair from the tate collection, London. J Anal Appl Pyrol 75(2):200-204

37. Muir K, Gautier G, Casadio F, Vila A (2011) Interdisciplinary investigation of early house paints: Picasso, Picabia and their "Ripolin" paintings. In: ICOM Committee for Conservation Preprints, Critério - Artes Gráficas, Lda, Bridgeland J. (Ed.), Lisbon, p. 23.

38. VVAA (2013) Surreal Picasso masterworks made with common house paint. New Sci 217(2904):19

39. Muir K, Langley A, Bezur A, Casadio F, Delaney J, Gautier G (2013) Scientifically investigating Picasso's suspected use of ripolin house paints in still life, 1922 and the red armchair, 1931. J Am Institute Conserv 52(3):156-172

40. Standeven HAL (2013) Oil-based house paints from 1900 to 1960: an examination of their history and development, with particular reference to ripolin enamels. J Am Institute Conserv 52(3):127-139

41. van der Weerd J, van Loon A, Boon J (2005b) FTIR studies of the effects of pigments on the ageing of oil. Stud Conserv 50:3-22

42. Favero PA, Mass J, Delaney JK, Woll AR, Hull AM, Dooley KA, Finnefrock AC (2017) Reflectance imaging spectroscopy and synchrotron radiation $\mathrm{X}$-ray fluorescence mapping used in a technical study of the blue room by pablo Picasso. Herit Sci 5(1):13

43. Sessa C, Jiménez de Garnica R, Rosi F, Fontana R, Garcia JF (2016) A Study of Picasso's painting materials and techniques in six of his early portraits. J Am Institute Conserv 55(4):198-216

44. Arslanoglu J, Centeno SA, Digney-Peer S, Duvernois I (2013) Picasso in the metropolitan museum of art: an investigation of materials and techniques. J Am Institute Conserv 52(3):140-155

45. Bratasz $Ł$, RezaSereshk MM (2018) Crack saturation as a mechanism of acclimatization of panel paintings to unstable environments. Stud Conserv 63(sup1):22-27

46. Giorgiutti-Dauphiné F, Pauchard L (2016) Painting cracks: a way to investigate the pictorial matter. J Appl Phys 120(6):065107

Publisher's Note Springer Nature remains neutral with regard to jurisdictional claims in published maps and institutional affiliations. 